Article

\title{
Parental Feeding Practices in Relation to Maternal Education and Childhood Obesity
}

\author{
Priscilla Ayine ${ }^{1}$, Vaithinathan Selvaraju ${ }^{1}$, Chandra M. K. Venkatapoorna ${ }^{1}$ and \\ Thangiah Geetha $1,2, *$ (D) \\ 1 Department of Nutrition, Dietetics, and Hospitality Management, Auburn University, Auburn, AL 36849, \\ USA; pza0022@tigermail.auburn.edu (P.A.); vzs0041@auburn.edu (V.S.); iamchandru@gmail.com (C.M.K.V.) \\ 2 Boshell Metabolic Diseases and Diabetes Program, Auburn University, Auburn, AL 36849, USA \\ * Correspondence: thangge@auburn.edu; Tel.: +1-334-844-7418
}

Received: 3 March 2020; Accepted: 7 April 2020; Published: 9 April 2020

\begin{abstract}
Parental beliefs, attitudes, and feeding practices play a vital role in childhood obesity. This study aimed to assess parental perceptions, concerns about weight, feeding practices using the Child Feeding Questionnaire (CFQ), and its association with body mass index (BMI) and maternal education in elementary school children. Participants aged 6-10 years $(n=169)$ were recruited and anthropometric measurements were obtained. Pearson's correlation and hierarchical linear regression analysis were used to examine the association between BMI $z$-score and the seven factors of the CFQ. The BMI $z$-score was significantly associated with parental perceived child weight and concern about child weight. The BMI $z$-score had a significant negative association with parents pressuring children to eat. Parents of obese children reported significantly higher $(p<0.001)$ levels of perceived child weight ( $\beta=0.312)$ and concern $(\beta=0.320$ ) about their child's weight compared to the normal weight and overweight groups. Parents of overweight children showed considerably less $(\beta=-0.224 ; p<$ 0.005 ) pressuring towards their children to eat as compared to parents of normal weight children. Additionally, we found that the parental feeding practice (pressure to eat) was only dependent upon maternal education. The path analysis indicates that maternal education has a mediating effect on BMI $z$-score and pressure to eat is related to BMI $z$-score through maternal education. The findings demonstrate the association between the parents' perceptions, concerns, and pressure to eat with BMI $z$-score of elementary school-aged children. Only the parental feeding practice pressure to eat was dependent upon the maternal education.
\end{abstract}

Keywords: parental feeding practices; child weight status; obesity; parental perceptions

\section{Introduction}

Although childhood obesity has received significant attention over the past few decades, it remains a major public health concern [1]. In the United States, childhood obesity has tripled in the past decade. It is estimated that about 13.7 million children and adolescents are currently obese in the United States [2]. In Alabama, more than $36 \%$ of children are overweight and obese, and it is the 5th highest ranked state in obesity [3]. Obesity is typically characterized by an increase in body fat mass [4]. The common causes of childhood obesity include diet, behavioral, and genetic factors [5]. Chronic diseases such as type 2 diabetes mellitus, hypertension, and hypercholesterolemia have been established to be associated with obesity [6]. The persistence of childhood obesity into adulthood and its connection with morbidity is a major problem [7]. Additionally, childhood obesity is associated with several short and long-term health adverse effects, so it is crucial to identify early and address it with efficient methods. This includes metabolic disease [8], cardiovascular related disease [9-12], retinal and renal problems $[13,14]$, and nonalcoholic fatty liver disease $[15,16]$. The transition of world 
nutritional changes starts with a high intake of processed food, sugary food, beverages, artificial juice, and drinks [17]. Children learn about the food context in their earlier periods from their families. Children's first nutritional educators are their parents, and they channelize their food context and eating behavior. Parental beliefs and feeding practices play a very critical role in shaping the eating behaviors of children. The eating habits and physical activity of children are influenced mainly by parental beliefs and perceptions [18]. Furthermore, parents' educational level has been found to affect their ability to process health information, leading to improved health-related decisions. The new health information drives their inspiration to adopt a healthy lifestyle as role models for their children [19,20]. Though maternal education level has been established to play a role in feeding practices of their children, not many studies have been conducted to examine the influence of maternal education on parents' perceptions, concerns, and feeding practices in regard to child weight. Therefore, this study will fill the gap in information to examine the relationship between parental perception, feeding practices with children's BMI, and maternal education using the Child Feeding Questionnaire (CFQ).

The CFQ is a self-reported instrument often used to assess parental feeding attitudes, beliefs, and susceptibility to obesity [21,22]. The association between parental feeding practice and obesity is not consistent across studies. Research conducted from the UK and Australia did not show the association between parental restriction and child weight [23-25]. The longitudinal study showed no correlation between pressure to eat and childhood obesity measures [25,26]. A further few studies conducted in children showed parental feeding practice varied across their ethnicity and socioeconomic status [24]. In another study, less restrictive feeding practice was positively associated with child weight status in Swedish children [27]. The systemic reviews showed the investigation of maternal feeding practice concerning children's dietary intake, and BMI has focused on feeding practice [28-30]. The present study hypothesizes the existence of association between the parents' perceptions, concerns, and feeding practices with children's BMI z-score and maternal education in elementary school-aged children. The age groups (6 to 10 years) of the study participants reflect when the child matures and starts to eat outside the house environment, though they still are affected by parents' control in their feeding practice and selection of food [31].

In the present study we asked two questions: first, to what extent are parents' perceptions, concerns, and feeding practices related with the obesity of children? Second, are any of the associated factors correlated with maternal education? For this we investigated the association between BMI $z$-score and the seven factors of the CFQ. In addition, we examined the influence of maternal education on the factors that were significantly associated with BMI z-score.

\section{Materials and Methods}

\subsection{Participants and Data Collection}

Participants were 169 children aged 6-10 years from the Lee and Macon counties in Alabama. A study flyer was designed and distributed in and around the area. Participants were recruited at home schools, after-school programs, through friends, and through participant referrals. Parents interested in participating in the study reached out either by email or phone. Participants younger than 6 years and older than 10 years, with medical conditions such as diabetes, cardiovascular disease, or sleep apnea and those taking any medications were excluded from the study based on phone interview. Parents came with their children to Auburn University for anthropometric measurements and to complete questionnaires. In addition, the same participants were used to determine the relationship between obesity and sleep timing behavior [32]. Maternal education was collected and categorized as high school or less, associate's degree, Bachelor's degree, or graduate degree. Written consent was obtained from the parents and participants. This study was approved by the Auburn University Institutional Review Board (Protocol \# 17-364 MR 1709). The appropriate sample size analyses were performed using $G^{*}$ Power 3.1.9.4. One way-Analysis of Variance (ANOVA) for three groups showed greater than 
power $(1-\beta)=0.80$ with $\alpha=0.05$ to detect 0.25 change (effect size) in the sample groups of minimum 159 participants.

\subsection{Anthropometric Measurements}

The bodyweight of the children was measured without shoes or heavy clothing to the nearest $0.1 \mathrm{~kg}$. The children's height was measured to the nearest $0.1 \mathrm{~cm}$ on a calibrated scale attached to a stadiometer. BMI was defined based upon the ratio of weight to height (squared) of the participants. The children were classified according to BMI percentile charts for age and sex from the Center for Disease Control and Prevention [2] as underweight (BMI $<5$ th), normal weight (BMI $\geq 5$ th to $<85$ th), overweight (BMI $\geq 85$ th to $<95$ th), and obese (BMI $\geq 95$ th) (CDC, 2015). Based on the WHO growth reference 2007 data, BMI $z$-score was calculated using SPSS macro adjusting for age and sex [33].

\subsection{Description of Factors in the Child Feeding Questionnaire (CFQ)}

The CFQ is a tool developed to measure parents' perceptions, concerns about child weight status, child-feeding attitudes, and practices [34]. It consists of 7 factors and 30 subscales. There are four factors to measure parents' perception and concern about weight and three factors to determine the parents' attitudes and feeding practices. The first factor in measuring parents' perception and concern about weight is perceived responsibility [26], which consists of 3 subscales measuring parents' perceived responsibility in feeding their child. The second factor is perceived parent weight (PPW), composed of 4 subscales that assess the history of the parents' perceptions of their weight status. The third factor is perceived child weight (PCW), which measures parents' perceptions of the weight status of their children from the time of birth. The fourth factor is the parental concern $(\mathrm{CN})$, consisting of 3 subscales and assessing parental concerns about their child's risk of being overweight. The remaining three factors measure parents' attitudes and feeding practices. The first factor of feeding practices includes restriction (RST) which measures the extent to which parents limit their child's access to food. The second factor is pressure to eat (PE) which assesses parents' tendency to pressure their children to eat more food. The final factor is monitoring (MN) which measures the extent to which parents supervise their child's eating. The abbreviations for the factors used in this manuscript are consistent with the original abbreviations presented in previous studies $[27,34]$ with minor modifications.

\subsection{Statistical Analysis}

The data were analyzed using Statistical Package for Social Sciences (SPSS) version 25.0 for Windows, IBM, and Armonk, NY, USA. Descriptive statistics are expressed as the mean \pm standard error or mean \pm standard deviation (SD). $p<0.05$ is considered as statistically significant. Analysis of variance (ANOVA) was used to compare the mean difference for participant's age, gender, maternal education, BMI, and BMI $z$-score. The distribution of predictive factors was evaluated for multicollinearity and normality (skewness). Log-transformation was done for more skewed data of child feeding questionnaire factors and used for hierarchical regression analysis. Cronbach's alpha was evaluated for items on each of the seven factors to assess internal consistency. Pearson's correlation was used to determine the relationships between the mean item scores for each of the seven factors in the CFQ and BMI $z$-score.

To determine which group of factors in the CFQ would predict BMI $z$-score of children, the following variables were accounted for: gender, age, and maternal education. We ran a hierarchical linear regression with BMI $z$-score as the dependent variable. All seven factors of the CFQ were the predictors and the potential confounding variables. Based on the maternal education status, participants' mean difference in the significant CFQ factors was analyzed by one-way ANOVA. A path analysis was conducted to identify the relation between the significant CFQ factors and BMI $z$-score. Furthermore, the direct and indirect effects were evaluated using maternal education as the mediating variable in the model. According to Kheirollahpour and Shohaimi [35], two paths are considered for testing the direct and indirect relationship in the model. One-way ANOVA was used to examine the 
mean difference for significant factors from the regression analysis (perceived child weight, parental concern, pressure to eat). Tukey's test was used for post-hoc comparison between groups.

\section{Results}

The descriptive characteristics of the study population are presented in Table 1. Sixty-four and a half percent $(n=109)$ of participants were normal weight $(\mathrm{NW}), 18.9 \%(n=32)$ were overweight $(\mathrm{OW})$, and $16.6 \%(n=28)$ were obese $(\mathrm{OB})$. The ages of participants ranged from 6 to 10 years with a mean age of 8.42 years for all the participants. There were no significant differences observed in age, gender, or maternal education. However, there was a significant difference in BMI z-score of the OW and the OB group compared to NW participants. The average score for the subscales for each factor in CFQ was calculated. Cronbach alpha for the CFQ factors was calculated for internal consistency and it ranged from 0.66 to 0.94 , as presented in Table 2. The minimum criteria of Cronbach alpha for acceptable reliability was above 0.60 [36].

Table 1. Descriptive characteristics of study population.

\begin{tabular}{ccccc}
\hline & NW & OW & OB & $p$ Value \\
\hline All & $109(64.5 \%)$ & $32(18.9 \%)$ & $28(16.6 \%)$ & \\
Age (y) & $8.37 \pm 1.44$ & $8.28 \pm 1.29$ & $8.77 \pm 1.46$ & 0.349 \\
Gender (\%) & & & & \\
Male & $50.46 \%$ & $50.0 \%$ & $42.86 \%$ & \\
Female & $49.54 \%$ & $50.0 \%$ & $57.14 \%$ & \\
Maternal Education (\%) & & & & \\
High School or less & $23.85 \%$ & $15.63 \%$ & $32.14 \%$ & \\
Associate Degree & $23.85 \%$ & $21.88 \%$ & $32.14 \%$ & \\
Bachelor's Degree & $20.18 \%$ & $28.13 \%$ & $21.43 \%$ & \\
Graduate & $32.11 \%$ & $34.38 \%$ & $14.29 \%$ & \\
BMI z-score & $-0.02 \pm 0.82$ & $1.56 \pm 0.26$ & $2.56 \pm 0.37$ & $p<0.001$ \\
\hline
\end{tabular}

$\mathrm{NW}=$ = Normal Weight; OW = Overweight and OB = Obese; BMI = Body mass index. The values are represented as mean \pm SD. Part of the data presented in the table was used in our previously published article [32].

Table 2. Cronbach Alpha of factors of the CFQ.

\begin{tabular}{ccc}
\hline Factor & Mean \pm SD & Cronbach Alpha \\
\hline PR & $3.41 \pm 0.70$ & 0.89 \\
PPW & $2.23 \pm 0.41$ & 0.66 \\
PCW & $1.97 \pm 0.31$ & 0.75 \\
CN & $0.94 \pm 1.19$ & 0.87 \\
RST & $2.59 \pm 0.97$ & 0.83 \\
PE & $1.69 \pm 1.18$ & 0.80 \\
MN & $2.89 \pm 1.12$ & 0.94 \\
\hline
\end{tabular}

Perceived Responsibility (PR), Perceived Parent Weight (PPW), Perceived Child Weight (PCW), Parental Concern about Child Weight (CN), Restriction (RST), Pressure to Eat (PE), and Monitoring (MN).

The bivariate correlation between the CFQ factors and BMI z-score is shown in Table 3. A significant positive correlation was observed between perceived child weight $(r=0.399)$, parental concern $(r=0.399)$, and BMI z-score. The strongest correlation between factors is shown in restriction and pressure to eat $(r=0.403)$; monitoring $(r=0.322)$, parental concern and restriction $(r=0.345)$, monitoring $(r=0.341)$, perceived child weight $(r=0.218)$, and restriction $(r=0.238)$ showed a positive correlation with perceived responsibility. Perceived child weight also showed correlation with monitoring $(r=0.321)$, parental concern $(r=0.302)$, and restriction $(r=0.171)$. Similarly, the magnitude of coefficient in pressure to eat and monitoring $(r=0.262)$, perceived parent weight, and concern $(r=$ $0.154)$ were reported. A significant negative correlation was observed between pressure to eat $(\mathrm{r}=$ $-0.177)$ and BMI z-score. 
Table 3. Pearson's correlations between CFQ factors and BMI z-score.

\begin{tabular}{ccccccccc}
\hline & BMI $z$-Score & PR & PPW & PCW & CN & RST & PE & MN \\
\hline BMI $z$-score & 1.000 & & & & & & & \\
PR & -0.031 & 1.000 & & & & & & \\
PPW & 0.122 & 0.008 & 1.000 & & & & & \\
PCW & $0.399 * *$ & $0.218^{* *}$ & 0.062 & 1.000 & & & & \\
CN & $0.399 * *$ & 0.115 & $0.154^{*}$ & $0.302 * *$ & 1.000 & & & \\
RST & 0.052 & $0.238^{* *}$ & 0.068 & $0.171^{*}$ & $0.345^{* *}$ & 1.000 & & \\
PE & $-0.177^{*}$ & 0.129 & -0.073 & -0.065 & 0.080 & $0.403^{* *}$ & 1.000 & \\
MN & 0.038 & $0.341^{* *}$ & -0.062 & $0.321^{* *}$ & 0.116 & $0.322^{* *}$ & $0.262^{* *}$ & 1.000 \\
\hline
\end{tabular}

Body mass index (BMI), Perceived Responsibility (PR), Perceived Parent Weight (PPW), Perceived Child Weight (PCW), Parental Concern about Child Weight (CN), Restriction (RST), Pressure to Eat (PE), and Monitoring (MN). * Correlation is significant at the 0.05 level (2-tailed). ${ }^{* *}$ Correlation is significant at the 0.01 level (2-tailed).

The hierarchical linear regression model was used to examine the association between BMI z-score (dependent variable) and the seven factors of the CFQ (independent variable). Gender, age of participants, and maternal education were entered into the model in the first step to adjust the potential confounding variables, followed by entering each of the predictors separately. This was done to help us observe the predictive power of each of the predictors as presented in the R square change seen in the table. The grouping of the subscales was done by averaging the subscales of each factor according to Birch et al. 2001 and Nowicka et al. 2015 [27,34]. The overall equation was statistically significant $\left(\mathrm{F}_{10,158}=8.665, p<0.001\right)$. About $34 \%$ of the variance in the child BMI $z$-score was explained by the child feeding questionnaire $\left(R^{2}=0.341\right.$, Adj. $\left.R^{2}=0.299\right)$. Perceived child weight $(B=7.644, \beta=0.312$, $\mathrm{t}=4.275, p<0.001)$, concern about child weight $(\mathrm{B}=1.691, \beta=0.320, \mathrm{t}=4.398, p<0.001)$, and parents pressuring children to eat $(\mathrm{B}=-1.342, \beta=-0.224, \mathrm{t}=-2.864, p=0.005)$ were significant factors in predicting child weight status. The other four factors were not statistically significant, as shown in Table 4 . The findings indicate that BMI z-score was positively associated with perceived child weight and parental concern and negatively associated with pressure to eat.

Table 4. Hierarchical linear regression analyses for BMI z-scores on CFQ factors.

\begin{tabular}{ccccc}
\hline CFQ Factor & B-Value & ${\text { Change in } \mathbf{R}^{\mathbf{2}}}$ & $\boldsymbol{\beta} \mathbf{( 9 5 \%}$ CI min, max) & $\boldsymbol{p}$ Value \\
\hline PR & -1.562 & 0.001 & $-0.108(-1.669,1.453)$ & 0.130 \\
PPW & 1.105 & 0.016 & $0.050(1.155,-1.055)$ & 0.454 \\
PCW & 7.644 & 0.165 & $0.312(7.956,-7.332)$ & $<\mathbf{0 . 0 0 1}$ \\
CN & 1.691 & 0.069 & $0.320(2.009,-1.369)$ & $<\mathbf{0 . 0 0 1}$ \\
RST & -0.531 & 0.014 & $-0.063(-0.595,0.469)$ & 0.427 \\
PE & -1.342 & 0.034 & $-0.224(-1.564,1.116)$ & $\mathbf{0 . 0 0 5}$ \\
MN & 0.164 & 0.000 & $0.023(0.187,-0.141)$ & 0.767 \\
\hline
\end{tabular}

The results were adjusted for the child's gender, age, and maternal education. Perceived Responsibility (PR), Perceived Parent Weight (PPW), Perceived Child Weight (PCW), Parental Concern about Child Weight (CN), Restriction (RST), Pressure to Eat (PE), Monitoring (MN). Statistically significant factors were represented in bold.

Since perceived child weight, parental concern, and pressure to eat were significantly associated with BMI z-score, we further compared the means of these significant predictors with the NW, OW, and $\mathrm{OB}$ groups using one-way ANOVA. Parents of children in the OB category reported significantly higher $(p<0.0001)$ levels of perceived child weight and parental concern compared to the NW and OW group. Parents of OW children showed considerably less $(p<0.05)$ pressuring their children to eat as compared to NW (Figure 1). 


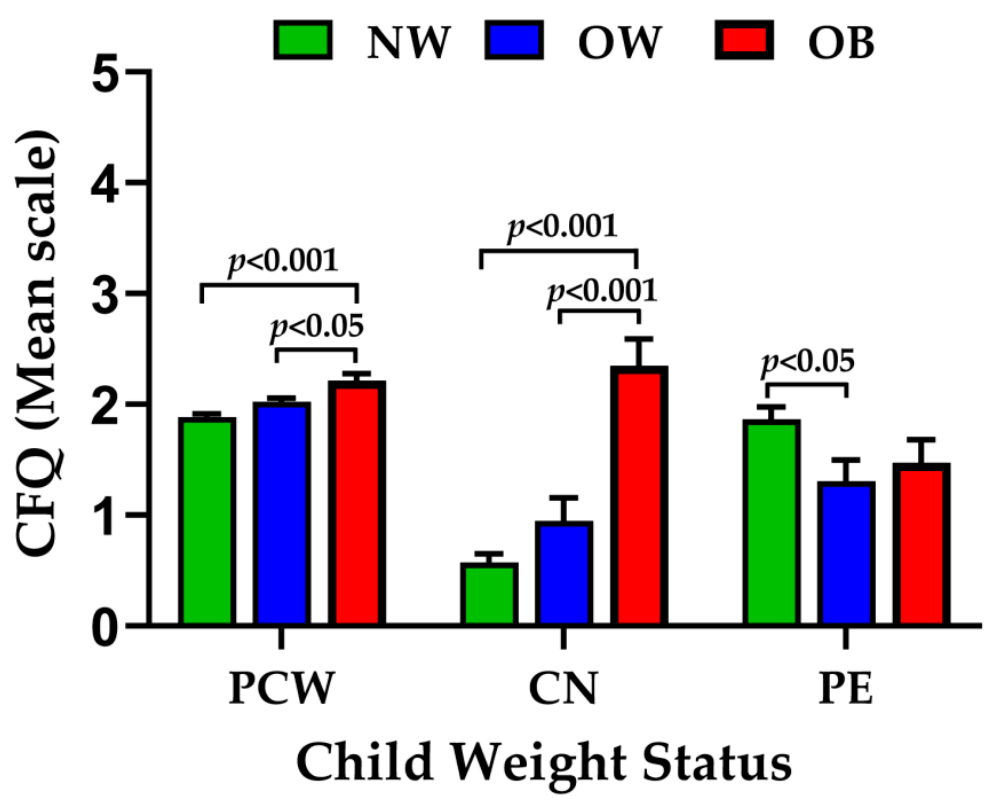

Figure 1. Bar graph showing the relation between the perceived child weight (PCW), parental concern $(\mathrm{CN})$, and pressure to eat $(\mathrm{PE})$ factors with the $\mathrm{NW}, \mathrm{OW}$, and $\mathrm{OB}$ participants. The values in the graph represent mean \pm SEM.

The relationship of these significant factors, perceived child weight, parental concern, and pressure to eat, with maternal education was determined. The one-way ANOVA result (Table 5) indicated that the children of mothers with high school or less education showed significantly high pressure to eat compared to other maternal education categories.

Table 5. One-way ANOVA of CFQ factors score with respect to the maternal education and weight categories.

\begin{tabular}{cccc}
\hline Maternal Education & PCW & CN & PE \\
\hline High School or less & $1.94(0.19)$ & $0.87(1.03)$ & $2.56(1.18)$ \\
Associate Degree & $1.94(0.37)$ & $1.35(1.38)$ & $1.88(1.18)^{*}$ \\
Bachelor's Degree & $2.09(0.36)$ & $0.74(1.10)$ & $1.09(0.96)^{* *}$ \\
Graduate & $1.92(0.30)$ & $0.79(1.16)$ & $1.29(0.88)^{* *}$ \\
\hline
\end{tabular}

Data are expressed as mean (SD); ${ }^{*} p<0.05$ and ${ }^{* *} p<0.0001$ are considered significant compared to the High School or less group. Perceived Child Weight (PCW), Parental Concern about Child Weight (CN), Pressure to Eat (PE).

These significant factors were further confirmed by the path model which provided an acceptable fit to the data $\left(\chi^{2}=31.786, \mathrm{df}=12, p=0.001, \mathrm{CFI}=0.812\right.$, RMSEA $\left.=0.09\right)$ [37]. As presented in Figure 2, pressure to eat had a significant negative relation with maternal education $(B=-1.53, p<0.001)$ and BMI z-score $(\mathrm{B}=-2.15, p<0.001)$. Maternal education had a negative relation with child $\mathrm{BMI} \mathrm{z}$-score $(\mathrm{B}=-0.23, p=0.002)$. Parental concern $(\mathrm{B}=1.61, p<0.001)$ and perceived child weight $(\mathrm{B}=7.11$, $p<0.001$ ) had a positive relation with child BMI z-score and no significant relation with maternal education. In the model, the largest effect was observed from PE to maternal education. To test the direct and indirect effects, the three significant factors (perceived child weight, parental concern, and pressure to eat) were tested from the regression model through maternal education as a mediating variable. Table 6 shows that pressure to eat solely indirectly predicted BMI z-score through maternal education $(B=0.49, p<0.002)$ and maternal education directly predicted $B M I z$-score $(B=-0.23)$. 


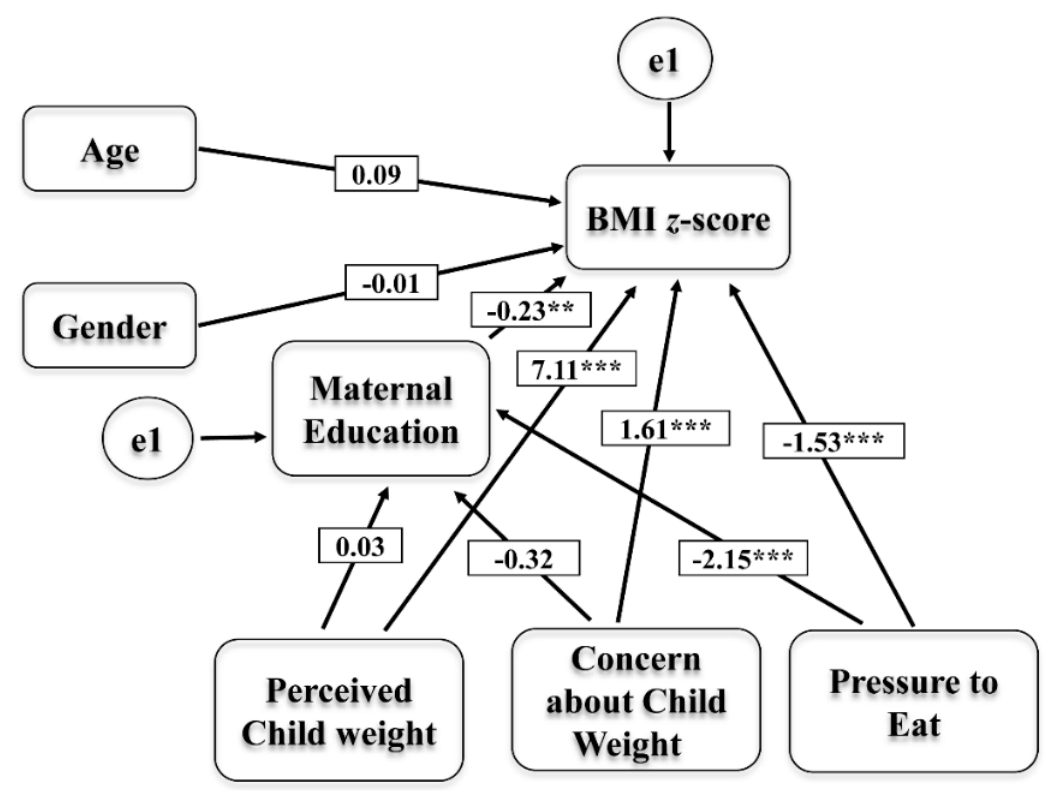

Figure 2. Path model showing the direct and indirect relation of the Perceived Child Weight, Parental Concern, and Pressure to Eat factors with BMI z-score through maternal education. Significant levels are $^{* *} p<0.01$ and ${ }^{* * *} p<0.0001$.

Table 6. Perceived Child Weight, Concern about Child Weight, and Pressure to Eat Related to BMI z-score through Maternal Education.

\begin{tabular}{ccccc}
\hline Parameters & Model & Variables & B & $p$-Value \\
\hline \multirow{2}{*}{ Perceived Child } & Direct Relationship & Perceived Child Weight $\rightarrow$ BMI z-score & 7.11 & 0.008 \\
Weight & Indirect Relationship & PCW $\rightarrow$ Maternal Education $\rightarrow$ BMI z-score & -0.007 & 0.992 \\
& Total effect & Direct + Indirect & 7.10 & 0.008 \\
\hline \multirow{2}{*}{ Concern about } & Direct Relationship & CN $\rightarrow$ BMI z-score & 1.61 & 0.004 \\
Child Weight & Indirect Relationship & $\mathrm{CN} \rightarrow$ Maternal Education $\rightarrow$ BMI z-score & 0.074 & 0.262 \\
& Total effect & Direct + Indirect & 1.69 & 0.004 \\
\hline \multirow{2}{*}{ Pressure to Eat } & Direct Relationship & PE $\rightarrow$ BMI z-score & -1.53 & 0.004 \\
& Indirect Relationship & PE $\rightarrow$ Maternal Education $\rightarrow$ BMI z-score & 0.49 & 0.002 \\
& Total effect & Direct + Indirect & -1.04 & 0.016 \\
\hline
\end{tabular}

$\mathrm{B}=$ Unstandardized parameter estimates. Perceived Child Weight (PCW), Parental Concern about Child Weight $(\mathrm{CN})$, Pressure to Eat (PE).

\section{Discussion}

This study uses the CFQ as a tool to assess the relationship between the parent's perception, concerns, and feeding practices with the children's BMI $z$-score and maternal education. The internal reliability determined by Cronbach's alpha was acceptable to excellent for the factors used. Three out of the seven factors (PCW, CN, PE) of the CFQ were found to be significant predictors of child BMI $z$-score using Pearson's correlation analysis. The perceived child weight and parental concern measure the parental perceptions and concerns about child weight. The perceived child weight and parental concern were positive indicators of child BMI $z$-score. Pressure to eat, measuring the parental feeding practices, was negatively influenced by the BMI $z$-scores, as reported by several other studies [38-41]. We found that more parents perceive their child's weight and show a significantly higher level of concern when their child is obese, which is similar to other studies [42-44]. Furthermore, parents place less pressure on their overweight and obese children to eat compared to normal weight children $[24,27,38]$. The parental beliefs, attitudes, and feeding practices can be altered to reduce obesity [41]. However, in several studies, there are discrepancies in the relationship between parental feeding practices and obesity. Other studies found restriction to be a significant predictor of child BMI $z$-score. Restriction was not a 
significant predictor in our study and this may be due to the age difference of the participants [27,38]. However, no relationship is found between parental restriction and obesity in studies conducted in Australia and the United Kingdom [23,25,45]. Similarly, the pressure to eat is found not to be associated with obesity in longitudinal studies $[25,26]$. In agreement with our results, the correlation analysis found that BMI z-score was negatively correlated with pressure to eat among children aged 2-4 years [46]. Populations from low-income are known to be affected more by obesity [47,48]. Education may offer mothers with the awareness of the importance of nutrition in health, knowledge of children's weight status as a risk factor for health problems in future, and maintains a good feeding practice to help in keeping a healthy weight [49]. The relationship between socio-economic status and parental feeding practices has been studied, but the results are not consistent [25,50,51]. Hence, the impact of maternal education was evaluated on the factors that were significantly associated with obesity: perceived child weight, parental concern, and pressure to eat. The parental feeding practice pressure to eat was only dependent upon maternal education. Mothers with a high school or less education pressurized their children to eat more when compared to mothers with higher education levels. This was confirmed with the path model showing that perceived child weight, parental concern, and pressure to eat were significantly associated with BMI z-score, but PE was only significantly related to maternal education. The study conducted by Nowicka et al 2014, describes that child BMI had direct relation to restriction, whereas pressure to eat was influenced by parental education [27]. The path model indicated that maternal education had a mediating and a direct effect on BMI z-score. Pressure to eat is related to BMI z-score and to a certain extent through maternal education. Maternal education may play a vital important role in the parental feeding practices and BMI of children. A study carried out by Cardel et al. (2012) found that socioeconomic status was negatively associated with restriction and pressure to eat [24], but our results showed maternal education was inversely related only with pressure to eat. The findings of this current study should be interpreted under this limitation. Although participants were recruited from Lee and Macon counties in Alabama, the sample cannot be considered a representation of Alabama children. The results are based upon a relatively small number of participants and a low percentage of obese participants. Another limitation of this study is that it is a cross-sectional study, but not a longitudinal study. The information obtained from these studies may not be sufficient to understand the disease trend. The cross-sectional study design provides us information about the prevalence of disease outcomes to design the cohort or longitudinal studies and gives the estimates to study the association of this study.

\section{Conclusions}

This study has furthered scientific understanding of the relation between parental perceptions, concerns, and feeding practices with the child's obesity and maternal education. Our findings show that perceived child weight and parental concern were positively associated with BMI z-score. And the pressure to eat was negatively associated with BMI z-score of elementary school-aged children. Out of these factors, the parental feeding practice pressure to eat was only dependent upon maternal education.

Author Contributions: Conceptualization, P.A., V.S., T.G.; methodology, P.A., V.S., C.M.K.V.; formal analysis, P.A., V.S., C.M.K.V.; writing-original draft preparation P.A.; writing-review and editing, all; visualization, T.G.; project administration, T.G.; supervision, T.G., funding acquisition, T.G. All authors have read and agreed to the published version of the manuscript.

Funding: This work was supported by the Alabama Agricultural Experiment Station and the Hatch Program of the National Institute of Food and Agriculture Hatch, U.S. Department of Agriculture to TG.

Acknowledgments: We would like to thank all the children for their participation and Miller Writing Center, Auburn University for editing this manuscript.

Conflicts of Interest: No potential conflict of interest was reported by the authors. 


\section{References}

1. Sarrafzadegan, N.; Rabiei, K.; Nouri, F.; Mohammadifard, N.; Moattar, F.; Roohafza, H.; Haghjooy Javanmard, S.; Zarfeshani, S.; Pourmoghaddas, M. Parental perceptions of weight status of their children. ARYA Atheroscler. 2013, 9, 61-69. [PubMed]

2. CDC. Centers for Disease Control and Prevention, Obesity Prevalence USA: Childhood Obesity Facts, Prevalence of Childhood Obesity in the United States. Available online: https:/www.cdc.gov/obesity/data/ childhood.html (accessed on 19 September 2019).

3. CDC. Centers for Disease Control and Prevention, Obesity Prevalence USA: Division of Nutrition, Physical Activity, and Obesity, National Center for Chronic Disease Prevention and Health Promotion. Available online: https://www.cdc.gov/obesity/data/prevalence-maps.html (accessed on 19 September 2019).

4. Mattos, R.T.; Medeiros, N.I.; Menezes, C.A.; Fares, R.C.; Franco, E.P.; Dutra, W.O.; Rios-Santos, F.; Correa-Oliveira, R.; Gomes, J.A. Chronic Low-Grade Inflammation in Childhood Obesity Is Associated with Decreased IL-10 Expression by Monocyte Subsets. PLoS ONE 2016, 11, e0168610. [CrossRef] [PubMed]

5. Sahoo, K.; Sahoo, B.; Choudhury, A.K.; Sofi, N.Y.; Kumar, R.; Bhadoria, A.S. Childhood obesity: causes and consequences. J. Fam. Med. Prim. Care 2015, 4, 187-192. [PubMed]

6. Must, A.; McKeown, N.M. The Disease Burden Associated with Overweight and Obesity. In Endotext; Feingold, K.R., Anawalt, B., Boyce, A., Chrousos, G., Dungan, K., Grossman, A., Hershman, J.M., Kaltsas, G., Koch, C., Kopp, P., et al., Eds.; MDText.com, Inc.: South Dartmouth, MA, USA, 2012.

7. Antonino, B.; Caterina, M.; Marianna, B.; Felicia, F.; Antonio, P. Parental perception of childhood obesity in an inner-city area of Palermo, Italy. Ital. J. Pub. Health 2008, 5, 241-248.

8. Owens, S.; Galloway, R. Childhood obesity and the metabolic syndrome. Curr. Atheroscler Rep. 2014, 16, 436. [CrossRef]

9. Bridger, T. Childhood obesity and cardiovascular disease. Paediatr. Child Health 2009, 14, 177-182. [CrossRef]

10. Litwin, S.E. Childhood Obesity and Adulthood Cardiovascular Disease. J. Am. Coll. Cardiol. 2014, 64, 1588-1590. [CrossRef]

11. Umer, A.; Kelley, G.A.; Cottrell, L.E.; Giacobbi, P., Jr.; Innes, K.E.; Lilly, C.L. Childhood obesity and adult cardiovascular disease risk factors: a systematic review with meta-analysis. BMC Pub. Health 2017, 17, 683. [CrossRef]

12. Yan, Y.; Hou, D.; Liang, Y.; Zhao, X.; Hu, Y.; Liu, J.; Cheng, H.; Yang, P.; Shan, X.; Xi, B.; et al. Tracking Body Mass Index From Childhood to Adulthood for Subclinical Cardiovascular Diseases at Adulthood. J. Am. Coll. Cardiol. 2016, 67, 1006-1007. [CrossRef]

13. Ding, W.; Cheung, W.W.; Mak, R.H. Impact of obesity on kidney function and blood pressure in children. World J. Nephrol. 2015, 4, 223-229. [CrossRef]

14. Savige, J.; Ratnaike, S.; Colville, D. Retinal abnormalities characteristic of inherited renal disease. J. Am. Soc. Nephrol. 2011, 22, 1403-1415. [CrossRef] [PubMed]

15. Kodhelaj, K.; Resuli, B.; Petrela, E.; Malaj, V.; Jaze, H. Non-alcoholic fatty liver disease and non-alcoholic steatohepatitis in Albanian overweight children. Minerva Pediatr. 2014, 66, 23-30. [PubMed]

16. Mathur, P.; Das, M.K.; Arora, N.K. Non-alcoholic fatty liver disease and childhood obesity. Indian J. Pediatr. 2007, 74, 401-407. [CrossRef]

17. Popkin, B.M. Contemporary nutritional transition: determinants of diet and its impact on body composition. Proc. Nutr. Soc. 2011, 70, 82-91. [CrossRef] [PubMed]

18. Ruggieri, D.G.; Bass, S.B. A comprehensive review of school-based body mass index screening programs and their implications for school health: do the controversies accurately reflect the research? J. Sch. Health 2015, 85, 61-72. [CrossRef] [PubMed]

19. Pulsifer, D.P.; Lakhtakia, A.; Narkhede, M.S. Education and Health: Evaluating Theories and Evidence. NBER Work. Pap. 2006, 10, 129-138.

20. Wolfson, J.A.; Gollust, S.E.; Niederdeppe, J.; Barry, C.L. The role of parents in public views of strategies to address childhood obesity in the United States. Milbank $Q$ 2015, 93, 73-111. [CrossRef] [PubMed]

21. de Lauzon-Guillain, B.; Oliveira, A.; Charles, M.A.; Grammatikaki, E.; Jones, L.; Rigal, N.; Lopes, C.; Manios, Y.; Moreira, P.; Emmett, P.; et al. A review of methods to assess parental feeding practices and preschool children's eating behavior: the need for further development of tools. J. Acad. Nutr. Diet. 2012, 112, 1578-1602. [CrossRef] 
22. Vaughn, A.E.; Tabak, R.G.; Bryant, M.J.; Ward, D.S. Measuring parent food practices: a systematic review of existing measures and examination of instruments. Int. J. Beh. Nutr. Physic. Activ. 2013, 10, 61. [CrossRef]

23. Campbell, K.; Andrianopoulos, N.; Hesketh, K.; Ball, K.; Crawford, D.; Brennan, L.; Corsini, N.; Timperio, A. Parental use of restrictive feeding practices and child BMI z-score. A 3-year prospective cohort study. Appetite 2010, 55, 84-88. [CrossRef]

24. Cardel, M.; Willig, A.L.; Dulin-Keita, A.; Casazza, K.; Beasley, T.M.; Fernandez, J.R. Parental feeding practices and socioeconomic status are associated with child adiposity in a multi-ethnic sample of children. Appetite 2012, 58, 347-353. [CrossRef] [PubMed]

25. Webber, L.; Hill, C.; Cooke, L.; Carnell, S.; Wardle, J. Associations between child weight and maternal feeding styles are mediated by maternal perceptions and concerns. Eur. J. Clin. Nutr. 2010, 64, 259-265. [CrossRef] [PubMed]

26. Spruijt-Metz, D.; Li, C.; Cohen, E.; Birch, L.; Goran, M. Longitudinal influence of mother's child-feeding practices on adiposity in children. J. Pediatr. 2006, 148, 314-320. [CrossRef]

27. Nowicka, P.; Sorjonen, K.; Pietrobelli, A.; Flodmark, C.E.; Faith, M.S. Parental feeding practices and associations with child weight status. Swedish validation of the Child Feeding Questionnaire finds parents of 4-year-olds less restrictive. Appetite 2014, 81, 232-241. [CrossRef] [PubMed]

28. Blissett, J. Relationships between parenting style, feeding style and feeding practices and fruit and vegetable consumption in early childhood. Appetite 2011, 57, 826-831. [CrossRef] [PubMed]

29. Collins, C.; Duncanson, K.; Burrows, T. A systematic review investigating associations between parenting style and child feeding behaviours. J. Hum. Nutr. Diet. 2014, 27, 557-568. [CrossRef] [PubMed]

30. Shloim, N.; Edelson, L.R.; Martin, N.; Hetherington, M.M. Parenting Styles, Feeding Styles, Feeding Practices, and Weight Status in 4-12 Year-Old Children: A Systematic Review of the Literature. Front. Psychol. 2015, 6, 1849. [CrossRef]

31. Mais, L.A.; Warkentin, S.; Latorre Mdo, R.; Carnell, S.; Taddei, J.A. Validation of the Comprehensive Feeding Practices Questionnaire among Brazilian Families of School-Aged Children. Front. Nutr. 2015, 2, 35. [CrossRef]

32. Venkatapoorna, C.M.K.; Ayine, P.; Selvaraju, V.; Parra, E.P.; Koenigs, T.; Babu, J.R.; Geetha, T. The relationship between obesity and sleep timing behavior, television exposure, and dinnertime among elementary school-age children. J. Clin. Sleep Med. 2020, 16, 129-136. [CrossRef]

33. de Onis, M.; Onyango, A.W.; Borghi, E.; Siyam, A.; Nishida, C.; Siekmann, J. Development of a WHO growth reference for school-aged children and adolescents. Bullet. World Health Org. 2007, 85, 660-667. [CrossRef]

34. Birch, L.L.; Fisher, J.O.; Grimm-Thomas, K.; Markey, C.N.; Sawyer, R.; Johnson, S.L. Confirmatory factor analysis of the Child Feeding Questionnaire: a measure of parental attitudes, beliefs and practices about child feeding and obesity proneness. Appetite 2001, 36, 201-210. [CrossRef] [PubMed]

35. Kheirollahpour, M.; Shohaimi, S. Dimensional model for estimating factors influencing childhood obesity: path analysis based modeling. Sci. World J. 2014, 2014, 512148. [CrossRef] [PubMed]

36. Nunnally, J.C., Jr. Introduction to psychological measurement.; McGraw-Hill: New York, NY, USA, 1978.

37. Kline, R.B. Principles and Practice of Structural Equation Modeling; The Guilford Press: New York, NY, USA, 2005.

38. Parkinson, K.N.; Reilly, J.J.; Basterfield, L.; Reilly, J.K.; Janssen, X.; Jones, A.R.; Cutler, L.R.; Le Couteur, A.; Adamson, A.J. Mothers' perceptions of child weight status and the subsequent weight gain of their children: a population-based longitudinal study. Int. J. Obes. 2017, 41, 801-806. [CrossRef] [PubMed]

39. Galloway, A.T.; Fiorito, L.M.; Francis, L.A.; Birch, L.L. 'Finish your soup': counterproductive effects of pressuring children to eat on intake and affect. Appetite 2006, 46, 318-323. [CrossRef]

40. Matheson, D.M.; Robinson, T.N.; Varady, A.; Killen, J.D. Do Mexican-American mothers'food-related parenting practices influence their children's weight and dietary intake? J. Am. Diet Assoc. 2006, 106, 1861-1865. [CrossRef]

41. Savage, J.S.; Fisher, J.O.; Birch, L.L. Parental influence on eating behavior: conception to adolescence. J. Law. Med. Ethics 2007, 35, 22-34. [CrossRef]

42. Doub, A.E.; Small, M.; Birch, L.L. A call for research exploring social media influences on mothers' child feeding practices and childhood obesity risk. Appetite 2016, 99, 298-305. [CrossRef] 
43. Gemmill, A.W.; Worotniuk, T.; Holt, C.J.; Skouteris, H.; Milgrom, J. Maternal psychological factors and controlled child feeding practices in relation to child body mass index. Child Obes. 2013, 9, 326-337. [CrossRef]

44. Kral, T.V.; Moore, R.H.; Compher, C.W. Maternal concern about child weight in a study of weight-discordant siblings. Pub. Health Nurs. 2015, 32, 132-142. [CrossRef]

45. Carnell, S.; Wardle, J. Associations between multiple measures of parental feeding and children's adiposity in United Kingdom preschoolers. Obesity (Silver Spring) 2007, 15, 137-144. [CrossRef]

46. Gregory, J.E.; Paxton, S.J.; Brozovic, A.M. Pressure to eat and restriction are associated with child eating behaviours and maternal concern about child weight, but not child body mass index, in 2- to 4-year-old children. Appetite 2010, 54, 550-556. [CrossRef]

47. Ogden, C.L.; Lamb, M.M.; Carroll, M.D.; Flegal, K.M. Obesity and socioeconomic status in children and adolescents: United States, 2005-2008. NCHS Data Brief 2010, 1-8.

48. Shrewsbury, V.; Wardle, J. Socioeconomic status and adiposity in childhood: a systematic review of cross-sectional studies 1990-2005. Obesity (Silver Spring) 2008, 16, 275-284. [CrossRef] [PubMed]

49. Saxton, J.; Carnell, S.; van Jaarsveld, C.H.M.; Wardle, J. Maternal Education Is Associated with Feeding Style. J. Am. Diet. Assoc. 2009, 109, 894-898. [CrossRef] [PubMed]

50. Hennessy, E.; Hughes, S.O.; Goldberg, J.P.; Hyatt, R.R.; Economos, C.D. Parent behavior and child weight status among a diverse group of underserved rural families. Appetite 2010, 54, 369-377. [CrossRef] [PubMed]

51. Mulder, C.; Kain, J.; Uauy, R.; Seidell, J.C. Maternal attitudes and child-feeding practices: relationship with the BMI of Chilean children. Nutr. J. 2009, 8, 37. [CrossRef]

(C) 2020 by the authors. Licensee MDPI, Basel, Switzerland. This article is an open access article distributed under the terms and conditions of the Creative Commons Attribution (CC BY) license (http://creativecommons.org/licenses/by/4.0/). 